\title{
Photooxidative Stability of Polyurethane/Polycarbonate Blends
}

\section{E. Govorčin Bajsića,"* and E. Zdraveva ${ }^{\mathrm{b}}$}

${ }^{a}$ Department of Polymer Engineering and Organic Chemical Technology, Faculty of Chemical Engineering and Technology, University of Zagreb, Marulićev trg 19, 10000 Zagreb, Croatia

bepartment of Basic Natural and Technical Sciences, Faculty of Textile Technology, University of Zagreb, Prilaz baruna Filipovića 28a, 10000 Zagreb, Croatia
This work is licensed under a

Creative Commons Attribution 4.0 International License

doi: 10.15255/CABEQ.2017.1196

Original scientific paper Received: July 22, 2017 Accepted: May 23, 2018

In this work the photooxidative stability of polyurethane/polycarbonate (PU/PC) blends was studied. Poly (ester-urethane) elastomers based on polycaprolactone glycol and an aromatic type of diisocyanate (MDI) were synthesized by a prepolymer procedure. Blends of PU and PC with different weight ratios were prepared using a Brabender mixer. Thermal and mechanical properties were evaluated after UV irradiation (200 hours) performing DSC, DMA, TGA and tensile tests. DMA results indicated partial miscibility of PC and PU in the PU/PC blends with higher hard segment content, attributed to favourable interactions between the ester groups from the soft segments and urethane groups from the hard segments. The photochemical degradation of the polyurethane is associated with the scission of the urethane group and photooxidation of the central $\mathrm{CH}_{2}$ group between the aromatic rings. The processes of photooxidative degradation are less pronounced in PU/PC blends with higher hard segment content in the polyurethane.

Keywords:

polyurethane, polycarbonate, elastomers, polymer blends, UV irradiation

\section{Introduction}

Polyurethanes (PUs) and their blends have found applications in many fields, due to their excellent mechanical properties and resistance to oil, grease, and abrasion, as well as good processability. The use of PU is in the field of automotive, civil engineering and architecture, medical equipment, electronics, textile industry, etc. It is well known that most polymers absorb UV irradiation, which causes changes in their physical properties (cracking -microcracks or voids), chemical, and mechanical properties due to photo- and thermo-oxidative reactions $s^{1,2}$. The influence of the aging process on the polymer lifetime is of great interest among scientists. Photooxidation in aromatic urethanes is believed to take place via a quinonoid route. The urethane bridge oxidizes to a quinone-imide structure. This structure is a strong chromophore, resulting in the yellowing of urethanes. Polycarbonate (PC) is one of the most widely used engineering thermoplastics due to its excellent properties, such as transparency, high mechanical strength, good thermal stability, and flame retardancy ${ }^{3}$. PC has applications in architecture (e.g. window glass, corrosion protection, floors), medicine (medical equipment,

"Corresponding author: e-mail: egovor@fkit.hr contact lenses, dental fillings), car industry (car upholstery, interior parts), electronics (CDs, DVDs, mobile chambers), and lots of other fields. An important property, upon which its application in medicine is based on, is biocompatibility, which means that PC is the basic, essential element for the parts that are in direct or indirect contact with the patient. In the last years, polycarbonate mixtures have become very important commercially. In order to predict the mixture behaviour during its usage, one can simulate the real conditions in the laboratory with the help of an UV lamp. The processes of aging are long-term and if it is necessary to predict the time of polymer durability, methods for accelerated laboratory aging are applied. Polymer behaviour during aging can be predicted also with the monitoring of the physical and mechanical properties and chemical composition changes during laboratory aging. The mechanism of photooxidative degradation of polyurethanes is shown in Scheme $1^{4,5}$. The UV light in the presence of oxygen in the PU (I) results in the homolytic bond scission in the urethane group (III) and in the formation of free radicals.

Further decomposition and recombination of the primary radicals results in the formation of amino (IV) and carbodiimide (VI) structures with the polycondensation of isocyanates. In the presence of oxygen, the quinoid structure is formed (II), which 


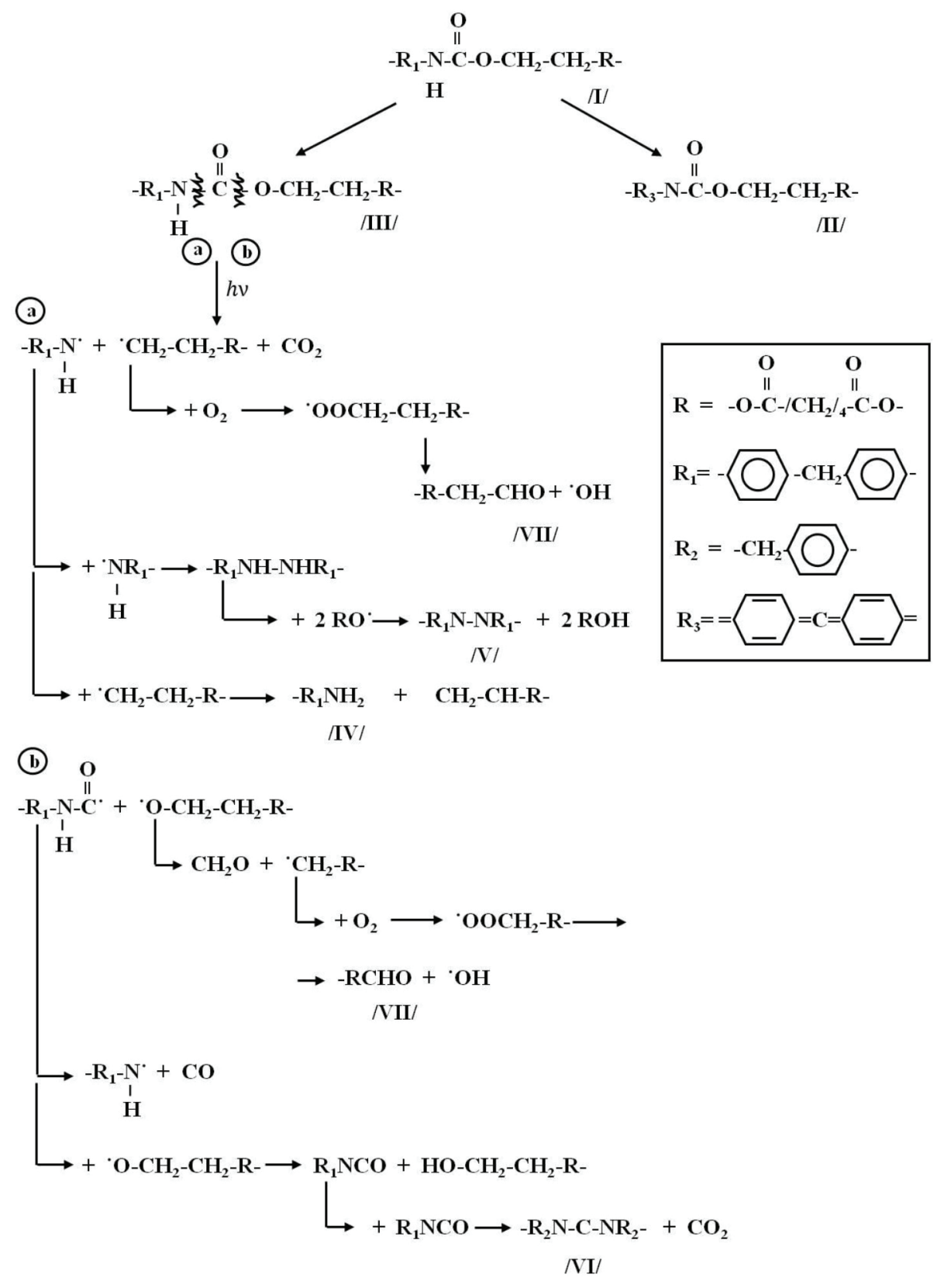

Scheme 1 - Mechanism of photooxidative degradation of $P U$

is characteristic for PU on the basis of diphenylmethane diisocyanate (MDI), as well as azo structure (V) and carbonyl structure (VII) with the reaction through hydroperoxide. The gas decomposition products are $\mathrm{CO}_{2}$ and $\mathrm{CO}$, and small amounts of $\mathrm{HCHO}$ and $\mathrm{H}_{2} \mathrm{O}$. With the listed reactions, other possible reactions are the reactions of crosslinking and secondary photochemical reaction.

The UV irradiation of the PC results in its photodegradation and bond scission of the carbonate group, followed by the methyl radical (rearrangement) migration to obtain two new compounds containing methyl ester group (1) and quinoide structure (2), according to Scheme $2^{6,7}$. With an increase in UV irradiation, there might be a change in the co- lour of the unirradiated PC, from transparent to yellow, confirming the formation of the quinoid group.

The purpose of the present work is twofold. First is the synthesis of poly (ester-urethane) elastomers (PU) based on poly (caprolactone) glycol, PCL, as soft segment and an aromatic type of diisocyanate (MDI) as the hard segment with different content of hard segment and the modification of PU elastomers with the polycarbonate (PC). Second is to examine the aging behaviour of PU/PC blends in an artificial weathering environment produced by UV chamber as weathering equipment, considering the importance of this characteristic for the final application of these blends in outdoor conditions. The investigation of photodegradability of $\mathrm{PU} / \mathrm{PC}$ blends 




Scheme 2 - Photodegradation of $P C$

is important for the final application of these blends in outdoor conditions (real conditions). Due to UV irradiation, PU/PC blends degrade in outdoor applications, therefore it is necessary to know what chemical degradation reactions occur. Also, after usage, these blends can be disposed in landfills and it is necessary to investigate the durability of these blends exposed to the outdoor environment, but most importantly to UV irradiation.

In this regard, several techniques were used to investigate the impact of hard segment content and UV aging on the characteristics of the studied PU/ PC blends. The influence on the transition temperatures, viscoelastic mechanical and thermal properties before and after UV exposure were monitored by differential scanning calorimetry (DSC), dynamic-mechanical analysis (DMA), thermogravimetric analysis (TGA) and stress-strain measurements.

\section{Experimental}

\section{Materials}

The materials used to produce PU/PC blends include the PU elastomers synthesised from aromatic 4,4' diphenylmethane diisocyanate, MDI (Desmodur M, Miles) and polycaprolactone glycol (PCL) (Tone 0230, Union Carbide Corp. of 1250 MW) and polycarbonate (PC -Makrolon 2805 with a melt flow index of $10 \mathrm{~g} / 10 \mathrm{~min}$ at $300{ }^{\circ} \mathrm{C}$ ) supplied by Bayer A. G., Germany. The PCL was dried overnight at $80{ }^{\circ} \mathrm{C}$ under a vacuum of $3 \mathrm{~mm} \mathrm{Hg}$. The diisocyanate and polycarbonate was used as received from the supplier. 1,4-butanediol was used as a chain extender.

\section{Sample preparation}

The PU elastomers were prepared in a two-step procedure. Firstly, prepolymers were synthesized at $80{ }^{\circ} \mathrm{C}$ under a nitrogen atmosphere in a stirred-glass reaction kettle. The diisocyanates (MDI) was charged into the kettle first, and heated to $80{ }^{\circ} \mathrm{C}$. An appropriate amount of PCL was then added, while $\mathrm{NCO} / \mathrm{OH}$ ratios of $2 / 1$ (35wt $\%$ of MDI) and 4/1 (52 wt $\%$ of MDI) were employed. The reaction was considered complete when the experimental value of the NCO concentration and the calculated value were within one percent. The NCO content of isocyanates and prepolymers was measured by the di(n-butyl) amine titration method (ASTM D163874). A chain extender 1,4-butanediol (1,4-BD) was added to the prepolymer with intensive mixing at a temperature of $90{ }^{\circ} \mathrm{C}$. In this work, 1,4-butanediol was primarily used as a chain extender, the prepolymers were extended with 1,4-butanediol to obtain the corresponding PU. After 60 seconds of mixing, the reaction mixture was immediately poured into a preheated Teflon-coated aluminium mould. This mixture was then heated to $100{ }^{\circ} \mathrm{C}$ in a Carver hydraulic platen press for about $30 \mathrm{~min}$. The elastomers were postcured in an oven for 24 hours at 105 ${ }^{\circ} \mathrm{C}$ immediately after moulding. The PU/PC blends were prepared by mixing of synthesised PU elastomers with $\mathrm{PC}$ in a Brabender mixer for 5 minutes using a temperature of $190{ }^{\circ} \mathrm{C}$ with a screw speed of $45 \mathrm{rpm}$. The blends were compression moulded into sheets $1 \mathrm{~mm}$ thick, using $100 \times 100 \mathrm{~mm}$ window frame moulds in a hydraulic press (Dake Model 44-226). The plates of the press were kept at 230 ${ }^{\circ} \mathrm{C}$ for $5 \mathrm{~min}$ for all the compositions of blends. The sheets were removed from the press after cooling to room temperature. For convenience, a code was used for each blend to identify their composition. After the abbreviation PU, a numeral denotes the $\mathrm{NCO} / \mathrm{OH}$ ratio in the prepolymer, followed by a numeral denoting the PU and $\mathrm{PC}$ content in each blend. PU2/PC 70/30 and PU4/PC 70/30 represent $\mathrm{PU} / \mathrm{PC}$ blends with $\mathrm{NCO} / \mathrm{OH}$ ratios of $2 / 1$ and $4 / 1$, respectively, and $70 \mathrm{wt} \%$ of $\mathrm{PU}$ and $30 \mathrm{wt} \%$ of $\mathrm{PC}$, Table 1.

\section{UV irradiation}

The UV irradiation of the PU elastomers, PC and PU/PC blends was carried out using a low-pressure mercury lamp unit (ultraviolet chamber Suntest Heraeus Suntest CPS xenon light lamp) at a temperature of $40{ }^{\circ} \mathrm{C}$, which emits radiation $\lambda=290$ $\mathrm{nm}$. The lighting system of Heraeus Suntest CPS xenon light lamp consists of an air-cooled xenon arc lamp with a quartz filter that emits a light the spectral distribution of which is very similar to that of sunlight. The xenon lamp is located in the roof of 
Table 1 - Composition of the samples

\begin{tabular}{lcc}
\hline \multicolumn{1}{c|}{ Sample designation } & PU wt $\%$ & PC wt $\%$ \\
\hline PU2 & 100 & 0 \\
PU4 & & \\
PU2/PC 70/30 & 70 & 30 \\
PU4/PC 70/30 & & \\
PU2/PC 50/50 & 50 & 50 \\
PU4/PC 50/50 & & \\
PU2/PC 30/70 & 30 & 70 \\
PU4/PC 30/70 & 0 & 100 \\
PC &
\end{tabular}

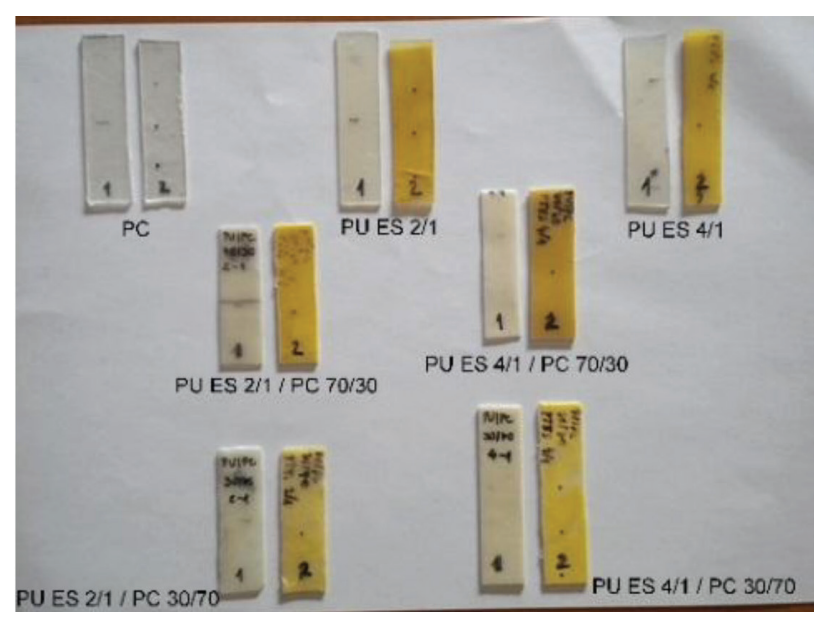

Fig. 1 - Photographs of samples before (1) and after (2) UV irradiation

the test chamber. The average light intensity was $747 \mathrm{~W} \mathrm{~m}^{-2}$, comparable to midday midsummer 40 "N latitude. The samples were irradiated for 200 hours.

\section{Effect of UV irradiation on the investigated samples}

Fig. 1 shows the samples of the PC, PU elastomers and PU/PC blends used in the work before and after 200 hours of UV irradiation.

According to Fig. 1, PC does not change its colour after UV irradiation, which might occur because of the quinoid structure formation after UV irradiation, while the PU elastomers and PU/PC blends show a colour change or yellowing after UV irradiation. It is related to the transformation of aromatic to the quinoid structures. During UV irradiation of the PU, photooxidative degradation results in the urethane group scission and oxidation of the central methylene group between two aromatic rings, which results in the quinoid structure formation and colouring of the PU (Scheme 3$)^{8}$.<smiles>COC(=O)Nc1ccc(Cc2ccc(NC(=O)OC)cc2)cc1</smiles><smiles>COC(=O)N=C1C=CC(=C=C2C=CC(=NC(=O)OC)C=C2)C=C1</smiles>

Scheme 3 - Oxidation of the central methylene group

The colour change, yellowing, is more evident in the PU4 elastomer and PU4/PC 70/30 blend.

\section{Differential scanning calorimetry analysis (DSC)}

Thermal properties evaluation was performed by differential scanning calorimetry, model Mettler Toledo DSC $822^{\mathrm{e}}$, before and after UV irradiation. Two heating cycles were used, the neat elastomers and PU/PC blends were first heated from $25^{\circ} \mathrm{C}$ to $250{ }^{\circ} \mathrm{C}$ under a nitrogen atmosphere $\left(40 \mathrm{~mL} \mathrm{~min}^{-1}\right)$ at a heating rate of $10{ }^{\circ} \mathrm{C} \mathrm{min}^{-1}$ and held for $5 \mathrm{~min}$ utes to eliminate their thermal history, and then cooled to $-100{ }^{\circ} \mathrm{C}$ at a cooling rate of $10{ }^{\circ} \mathrm{C} \mathrm{min}^{-1}$, and immediately reheated to $250{ }^{\circ} \mathrm{C}$. The thermograms refer to the second heating. The characteristic transition temperatures: melting $\left(T_{\mathrm{m}}\right)$ and crystallization $\left(T_{\mathrm{c}}\right)$ temperature were used as temperature in the peak.

\section{Dynamic mechanical analysis (DMA)}

Dynamic mechanical analysis was performed using a Dynamic Mechanical Analyser DMA 983, TA Instruments, over the temperature range of -100 to $250{ }^{\circ} \mathrm{C}$ at a frequency of $1 \mathrm{~Hz}$. The temperature ramping rate was $3{ }^{\circ} \mathrm{C} \min ^{-1}$. The analyses were performedin specimens measuring $25 \times 10 \times 1 \mathrm{~mm}$. All the samples were cooled to $-100{ }^{\circ} \mathrm{C}$ using the Liquid Nitrogen Cooling Accessory (LNCA). The DMA was conducted in duplicate, and the glass transition temperature $\left(T_{\mathrm{g}}\right)$ was determined using the maximum peak of loss modulus $(E$ ').

\section{Thermogravimetric analysis (TGA)}

Thermogravimetric analysis was performed on the thermal analyser TGAQ500, TA Instruments. The samples $\left(9-10 \mathrm{mg}\right.$ ) were heated from $25^{\circ} \mathrm{C}$ do $700{ }^{\circ} \mathrm{C}$ using heating rate of $10^{\circ} \mathrm{C} \mathrm{min}^{-1}$ in nitrogen atmosphere $\left(60 \mathrm{~mL} \mathrm{~min}^{-1}\right)$.

\section{Mechanical measurements}

Tensile properties were measured according to ISO 527 using Zwick 147670 Z100/SN5A appara- 
tus in uniaxial tension mode at $23{ }^{\circ} \mathrm{C}$ and $65 \%$ relative humidity. For the tensile tests, a crosshead speed of $50.00 \mathrm{~mm} \mathrm{~min}^{-1}$ was used. For each sample, five measurements were taken and average values calculated within standard deviation of $5 \%$.

\section{Results and discussion}

\section{Differential scanning calorimetry (DSC) analysis}

The technique of differential scanning calorimetry (DSC) was used to characterize the phase transitions: melting $\left(T_{\mathrm{m}}\right)$ and crystallization $\left(T_{\mathrm{c}}\right)$ temperature of the neat $\mathrm{PU}$ and $\mathrm{PC}$ and $\mathrm{PU} / \mathrm{PC}$ blends before and after UV irradiation. According to the results in Fig. 2 (Table 2), the PU2 elastomer shows the melting of the hard segment crystallites with a long-range order observed at $111.9^{\circ} \mathrm{C}\left(T_{\mathrm{ml}}\right)$. With the increase in the hard segment content in PU4 elastomer, the $T_{\mathrm{m} 1}$ of the hard segment was obtained at $165.4{ }^{\circ} \mathrm{C}$.

After UV irradiation in the PU4 elastomer, two melting temperatures of the hard segment appear $\left(T_{\mathrm{m} 1}=152.2{ }^{\circ} \mathrm{C}\right.$ and $\left.T_{\mathrm{m} 2}=184.3{ }^{\circ} \mathrm{C}\right)$, meaning that the hard segment is present in two different morphological structures (Table 2). This means that the crystallites of the hard segment divide into type I which is related to the higher level of phase miscibility, and type II related to the high level of immiscibility ${ }^{9}$. After UV irradiation, the crystallization temperature in PU4 elastomer decreases (from $T_{\mathrm{cl}}=$ 96.1 to $87.7^{\circ} \mathrm{C}$ ) due to the lower level of order in the hard segment. The DSC heating curves of the unirradiated and UV irradiated PU/PC blends with different content of the hard segment and PU and PC content are shown in Fig. 3. The DSC curve of all unirradiated PU2/PC blends shows only endo-
Table $2-D S C$ results before and after UV irradiation

\begin{tabular}{l|ccc|c|c}
\hline \multicolumn{1}{c|}{ Sample } & \multicolumn{3}{c|}{$T_{\mathrm{m} 1,2,3} /{ }^{\circ} \mathrm{C}$} & $T_{\mathrm{cl}} /{ }^{\circ} \mathrm{C}$ & $T_{\mathrm{c} 2} /{ }^{\circ} \mathrm{C}$ \\
\hline PU2 & 111.9 & - & - & 33.4 & - \\
PU2/PC 70/30 & - & - & - & - & - \\
PU2/PC 50/50 & - & - & 220.8 & - & - \\
PU2/PC 30/70 & - & - & 214.2 & - & - \\
\hline PU2 200 h UV & 115.7 & - & - & 35.6 & - \\
PU2/PC 70/30 200 h UV & 158.8 & - & 224.1 & - & 116.2 \\
PU2/PC 50/50 200 h UV & 160.1 & - & 222.1 & - & 113.4 \\
PU2/PC 30/70 200 h UV & 156.2 & 218.0 & 223.2 & - & 113.1 \\
\hline PU4 & 165.4 & - & - & 96.1 & \\
PU4/PC 70/30 & 154.6 & - & 222.9 & - & \\
PU4/PC 50/50 & 153.9 & - & 220.9 & - & \\
PU4/PC 30/70 & - & - & 220.0 & - & \\
\hline PU4 200 h UV & 152.2 & 184.3 & - & 87.7 & - \\
PU4/PC 70/30 200 h UV & 155.3 & 183.9 & 223.2 & 82.6 & 116.0 \\
PU4/PC 50/50 200 h UV & 160.3 & - & 221.3 & - & 113.8 \\
PU4/PC 30/70 200 h UV & 160.2 & - & 220.9 & - & 112.9 \\
\hline
\end{tabular}

thermic peak around $220^{\circ} \mathrm{C}$, which can be related to the melting of $\mathrm{PC}^{10}$. With the increase in the hard segment content at the ratios of PU4/PC 70/30, the endotherm at $154.6{ }^{\circ} \mathrm{C}$ is evidently related to $T_{\mathrm{m} 1}$ of the hard segment of $\mathrm{PU}$ and the melting endotherm of the PC around $220{ }^{\circ} \mathrm{C}$. The DSC curves of the $\mathrm{PU} 2 / \mathrm{PC}$ and PU4/PC blends with the content of 50 $\mathrm{wt} \%$ and $70 \mathrm{wt} \%$ of the PC show only melting endotherm of the $\mathrm{PC}$ which are at the same temperature $\left(220^{\circ} \mathrm{C}\right)$.

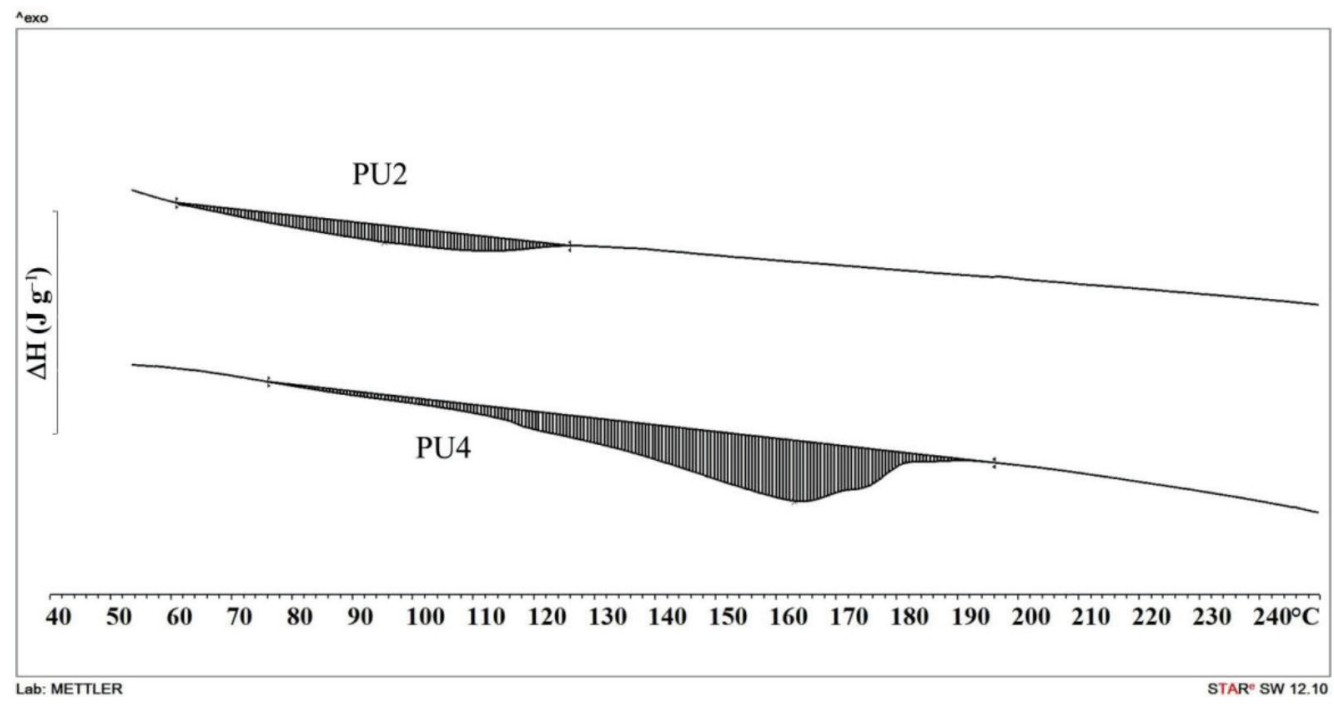

Fig. 2 - DSC heating curves of PU2 and PU4 elastomers before UV irradiation 



Fig. 3 - DSC heating curves of PU2/PC and PU4/PC: a) 70/30 b) 50/50 and c) 30/70 blends before and after UV irradiation

The melting peak is of high intensity for all PU2/PC and PU4/PC blends (melting peak $T_{\mathrm{m} 1}$ around $160{ }^{\circ} \mathrm{C}$ ) exposed to UV irradiation compared to unexposed blends. This could be ascribed to the oxidative degradation of the PU, which led to the formation of crosslinking structures with higher ordering. The cooling curves of the PU2/PC and
PU4/PC blends before and after UV irradiation are given in Fig. 4.

The cooling curves for all investigated blends obtained after UV irradiation show the appearance of the exothermic peaks of crystallinity, which shift to higher temperatures after UV irradiation. These crystalline domains in irradiated blends may be the 

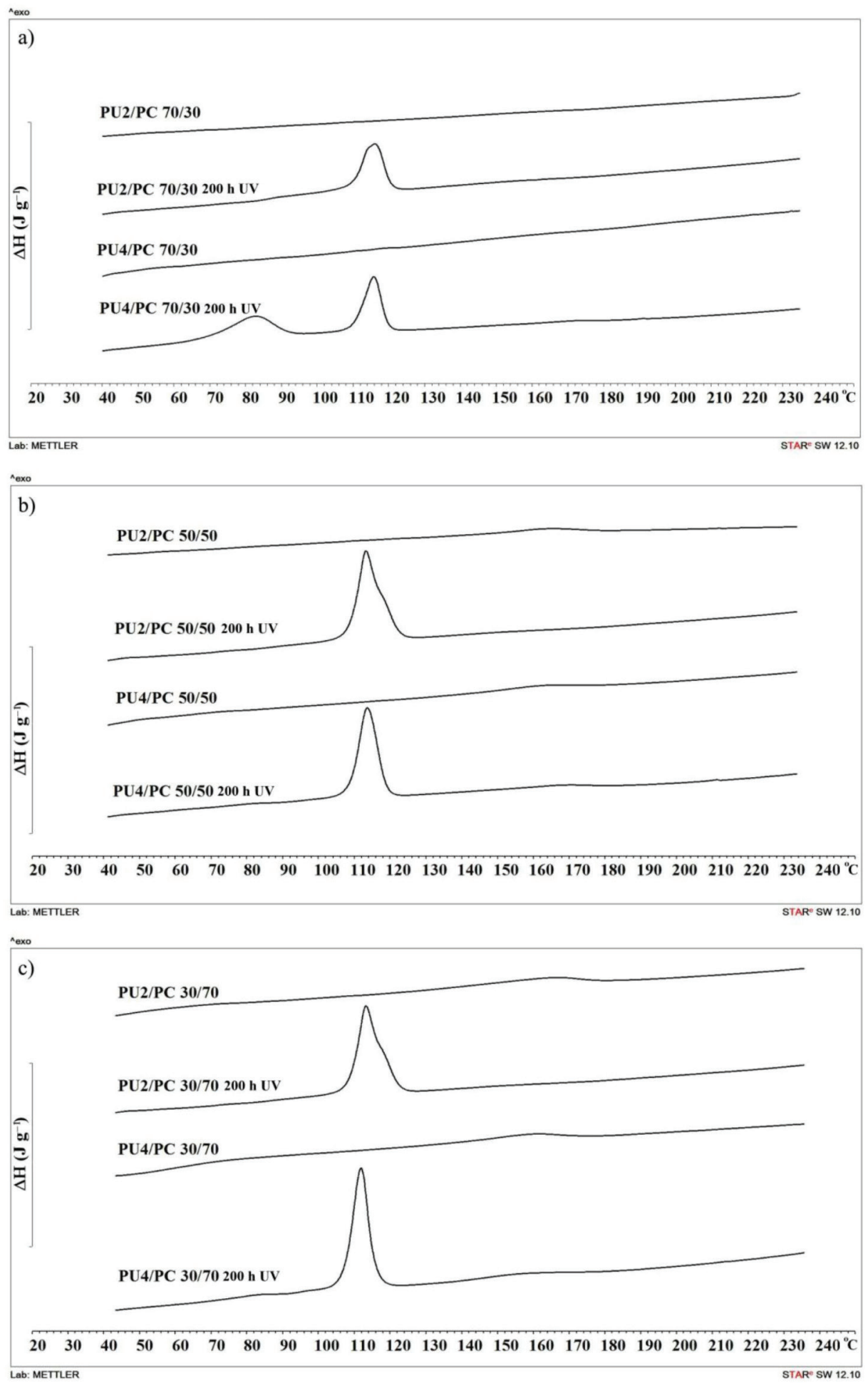

Fig. 4 - DSC cooling curves of PU/PC, a) 70/30, b) 50/50, and c) 30/70 blends before and after UV irradiation

result of crystallization process that occurs later (during storage) if the cooling rate is high ${ }^{11}$.

\section{Dynamic mechanical analysis results}

The DMA spectra of the blends can provide information of the degree of polymer-polymer interaction and interphase mixing. The results of glass transition temperature, $T_{\mathrm{g}}$ of the neat PU2 and PU4 elastomers before UV irradiation are summarised in Table 3. The soft segment $T_{\mathrm{g}}$ in the neat PU2 elastomer was found to be at $-15^{\circ} \mathrm{C}$, and it depends on the hard segment content ${ }^{12,13}$. The $T_{\mathrm{o}}$ of the soft segments increased from $-15{ }^{\circ} \mathrm{C}$ (for the neat PU2) to $2{ }^{\circ} \mathrm{C}$ with increasing in the hard segments content, 


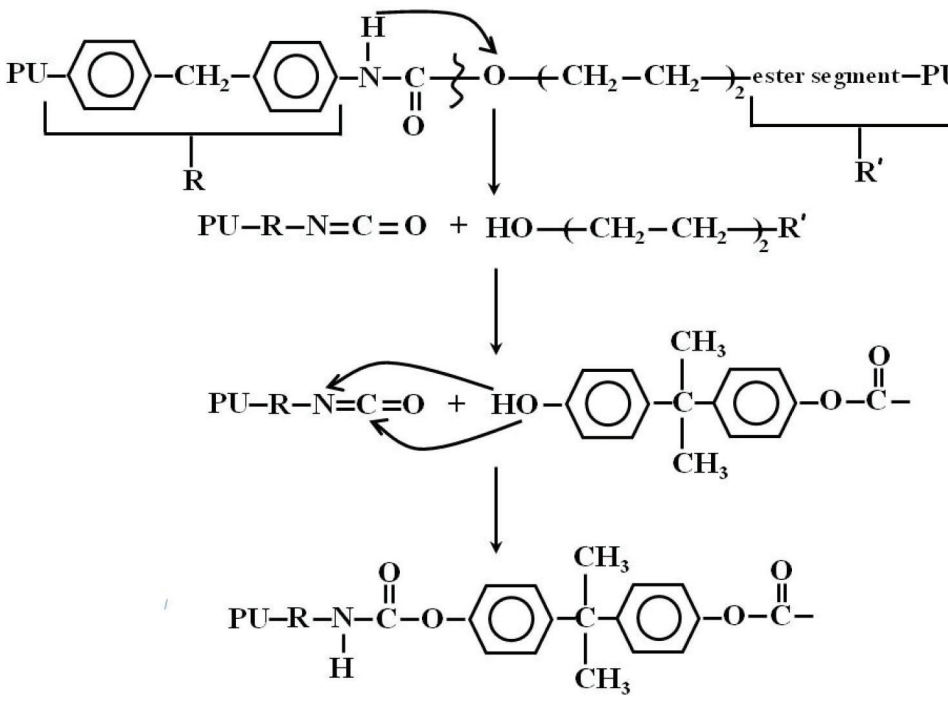

Scheme 4 -Formation of PU/PC copolymer

the neat PU4 elastomer. This behaviour could be explained by the lower separation between the soft and hard segments in PU4 elastomer. The chain mobility of the soft segments is restricted with increasing content of the hard segment, and increases the miscibility of the soft and hard segments, as indicated by the broadened maximum and reduced intensity on the $E " / T$ curve. The results of DMA obtained after UV irradiation indicated a slight increase in the $T_{\mathrm{g}}$ for the PU2, while for the PU4 elastomer, the $T_{\mathrm{g}}$ increased by $7^{\circ} \mathrm{C}$ after UV irradiation. This could be ascribed to oxidative degradation of the polyurethane, which led to the formation of a crosslinked structure, restricting the mobility of polymer chains, and thus $T_{\mathrm{g}}$ increased.

The loss modulus for the PU/PC blends of different compositions is presented as a function of temperature in Fig. 5. The incorporation of PC in the PU elastomers resulted in two relaxation peaks on the $E " / T$ curves. One relaxation peak at higher temperature corresponding to the $T_{\mathrm{g}}$ of the $\mathrm{PC}^{14}$, while the other peak at lower temperature corresponding to the $T_{\mathrm{g}}$ of the PU (Table 3 ). The obtained results in Fig. 5 show that the $T_{\mathrm{g}}$ shifted to higher temperature with increasing the hard segment content. One possible explanation could be that urethane groups of PU may interact with carbonyl groups from $\mathrm{PC}^{15,16}$. In general, the shift in the polyurethane $T_{\mathrm{g}}$ is more significant than the shift for the polycarbonate (Table 3 ). The $T_{\mathrm{g}}$ 's maxima of the PU and PC phases shift towards each other as the composition changes. This shift of the $T_{\mathrm{g}}$ gives an indication of possible partial miscibility of the PU and PC chains.

The new relaxation maximum around $80{ }^{\circ} \mathrm{C}$ was detected in DMA curves of PU2/PC 30/70 and PU4/PC 30/70 blends. This new relaxation maximum was attributed to interactions (chemical) at the a)

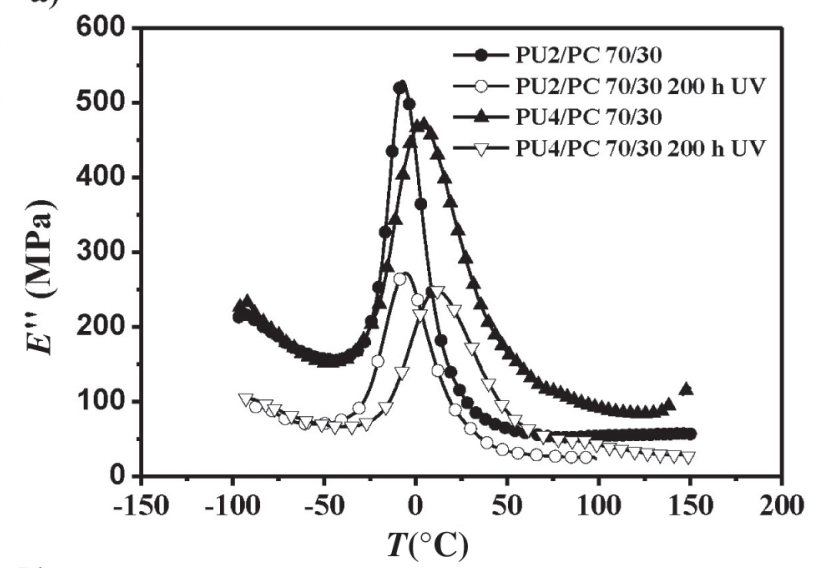

b)

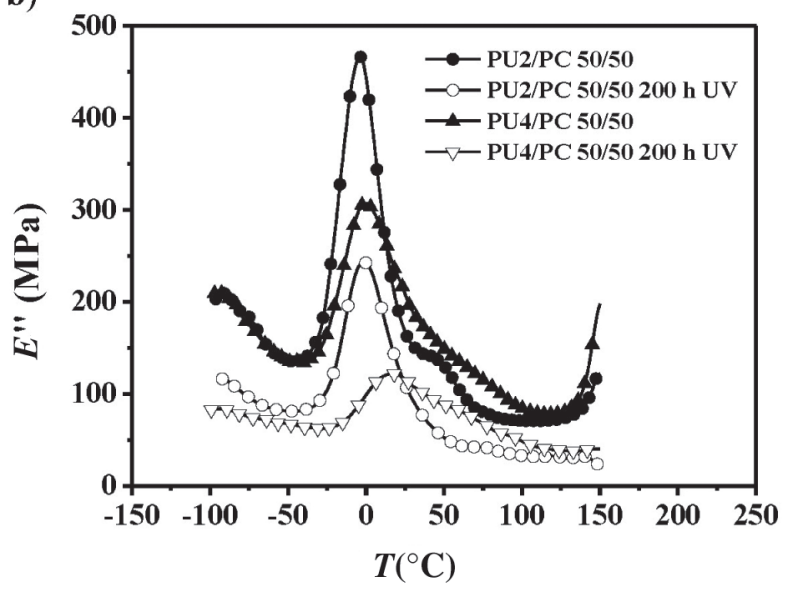

c)

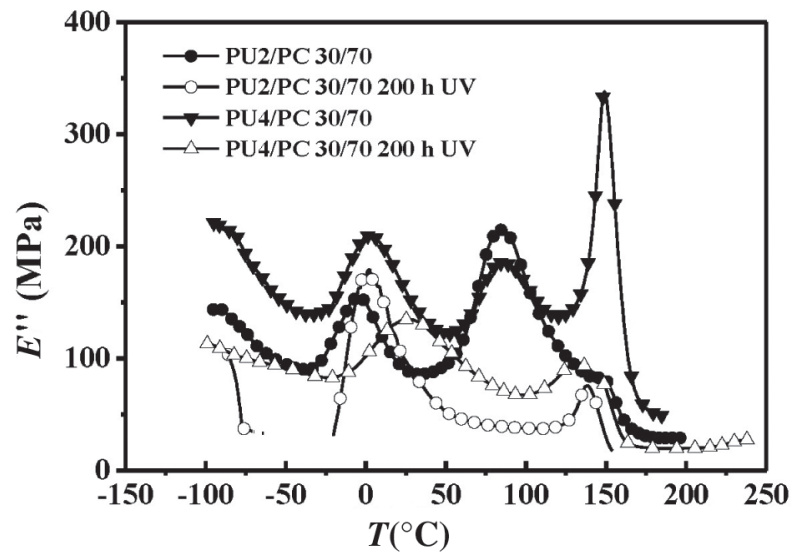

Fig. 5 - Loss modulus (E") for PU/PC a) 70/30, b) 50/50, and c) 30/70 blends as a function of temperature before and after UV irradiation

interface of PC-PU and partial miscibility of the PU and PC. In these PU/PC blends, the PC-PU copolymer was a result of the reaction between the $-\mathrm{OH}$ groups from the $\mathrm{PC}$ aromatic group and the $-\mathrm{NCO}$ groups of PU. The sequence of reactions that may have taken place is summarized in Scheme 4.

The temperature dependences of $E$ " of PU/PC blends after UV irradiation are shown in Fig. 5. The $T_{\mathrm{g}}$ of the blends obtained from the DMA is pre- 
Table 3 -DMA results before and after UV irradiation

\begin{tabular}{l|c|c|c|c|c}
\hline \multicolumn{1}{c}{ Sample } & $\begin{array}{r}T_{\mathrm{gPU}} \\
\left({ }^{\circ} \mathrm{C}\right)\end{array}$ & $\begin{array}{c}T_{\mathrm{gPC}} \\
\left({ }^{\circ} \mathrm{C}\right)\end{array}$ & $\begin{array}{c}I_{\mathrm{E}}{ }^{\prime} \mathrm{PU} \\
(\mathrm{MPa})\end{array}$ & $\begin{array}{c}I_{\mathrm{E} " \mathrm{PC}} \\
(\mathrm{MPa})\end{array}$ & $\begin{array}{c}E_{25^{\circ} \mathrm{C}} \\
(\mathrm{GPa})\end{array}$ \\
\hline PU2 & -14.6 & - & 693.1 & - & 0.090 \\
PU2/PC 70/30 & -7.1 & 147.5 & 527.3 & 56.7 & 0.373 \\
PU2/PC 50/50 & -4.0 & 150.1 & 465.8 & 121.9 & 2.067 \\
PU2/PC 30/70 & -4.2 & 148.3 & 214.4 & 154.4 & 3.260 \\
\hline PU2 200h UV & -13.9 & - & 288.5 & - & 0.110 \\
PU2/PC 70/30 200h UV & -5.7 & - & 271.5 & - & 0.440 \\
PU2/PC 50/50 200h UV & -0.9 & 139.6 & 243.2 & 32.1 & 0.950 \\
PU2/PC 30/70 200h UV & 1.9 & 138.2 & 178.0 & 75.5 & 1.470 \\
\hline PU4 & 2.2 & - & 459.8 & - & 1.050 \\
PU4/PC 70/30 & 3.4 & 151.4 & 471.0 & 118.7 & 2.731 \\
PU4/PC 50/50 & 0.0 & 151.2 & 307.3 & 198.4 & 3.398 \\
PU4/PC 30/70 & 3.1 & 149.1 & 333.1 & 209.5 & 4.833 \\
\hline PU4 200h UV & 8.4 & - & 471.4 & - & 1.050 \\
PU4/PC 70/30 200h UV & 11.9 & 146.2 & 243.5 & 27.8 & 1.730 \\
PU4/PC 50/50 200h UV & 16.5 & 148.9 & 121.8 & 40.4 & 1.560 \\
PU4/PC 30/70 200h UV & 26.4 & 131.8 & 134.9 & 96.3 & 2.670 \\
\hline PC & - & 149.0 & - & 272.2 & 2.170 \\
PC 200h UV & - & 150.5 & - & 413.7 & 2.390 \\
\hline
\end{tabular}

$T_{\mathrm{gPU}}-$ glass transition of the soft segment in PU; $T_{\mathrm{gPC}}-$ glass transition of the PC; $I_{\mathrm{E}^{\prime \prime} \mathrm{PU}}$ - intensity of the relaxation maxima of PU; $I_{\mathrm{E}^{\prime \prime} \mathrm{PC}}-$ intensity of the relaxation maxima of PC; $E_{25{ }^{\circ} \mathrm{C}}$ - storage modulus at $25^{\circ} \mathrm{C}$.

sented in Table 3. It can be seen that, after UV irradiation in all blends, especially in blends with higher hard segment content (PU4/PC blends), the $T_{\mathrm{g}}$ increased compared to unexposed blends. This behaviour could be attributed to the crosslinking mechanism after UV irradiation. The UV irradiation leads to oxidative degradation, which further leads to the formation of a crosslinking structure localised at the surface of the PCL, and as a consequence to an increase in the $T_{\mathrm{g}}^{11,17}$. The possible explanation could be in the restricted polymer molecules movement and reduction in the viscoelastic behaviour of energy dissipation in the blends ${ }^{18}$. Table 3 shows the values of the intensity of the relaxation maxima $\left(I_{\mathrm{E}, \mathrm{PU} ; \mathrm{PC}}\right)$ for the PU/PC blends before and after 200 hours of UV irradiation. It can be observed that the intensity of the relaxation maxima decreases and broadens after irradiation. This behaviour could be due to an increase in the distribution of molecular weight crosslinking or to an increase in the heterogeneity of crosslinking structure ${ }^{19}$.

The results of the storage modulus $\left(E^{\prime}\right)$ as a function of temperature $(T)$ for all investigated PU/ PC blends before and after UV irradiation (Fig. 6, Table 3) showed that, with the increase in hard segment content and PC content, the storage modulus increased. The observed result suggests partial miscibility of the PU and PC chains. a)

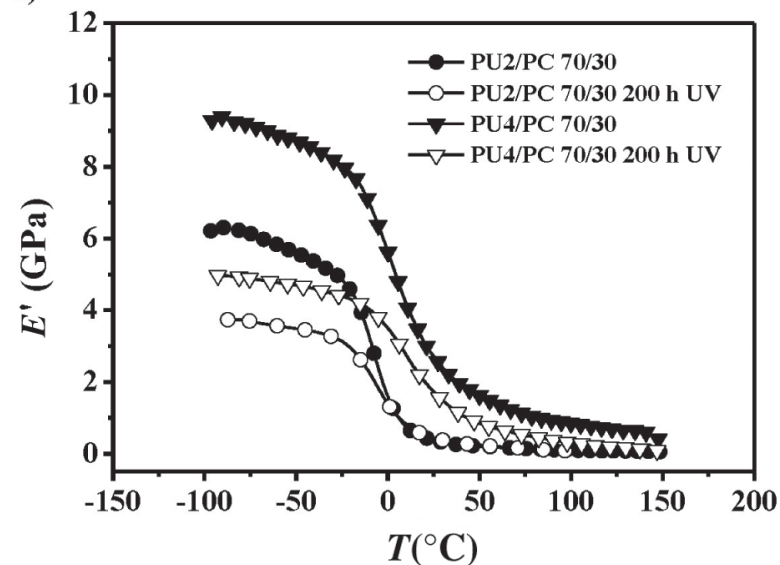

b)

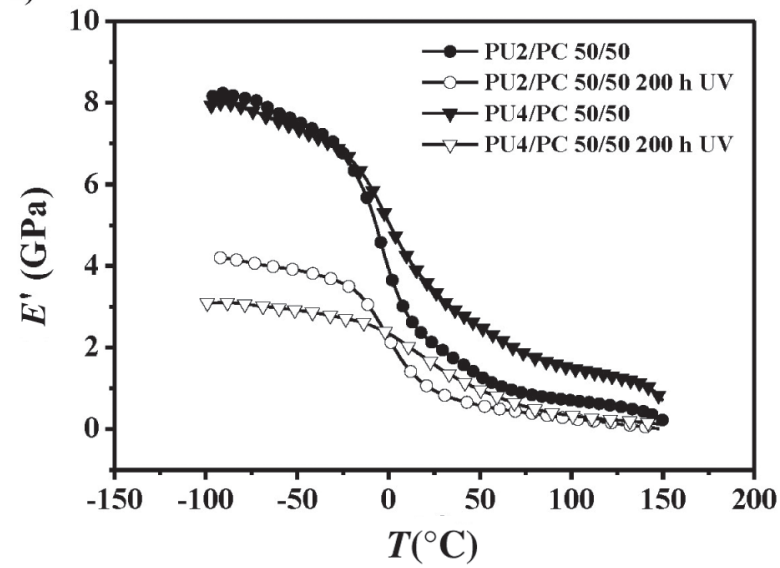

c)

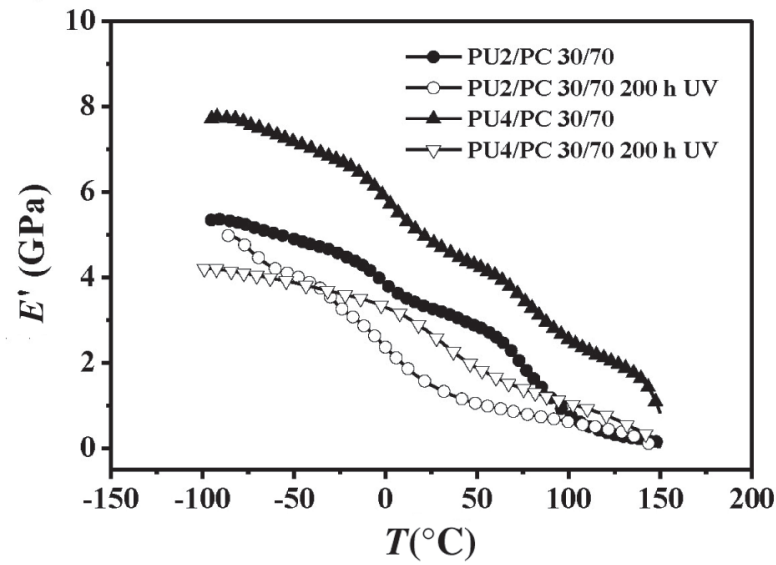

Fig. 6 - Storage modulus (E') for PU/PC a) 70/30, b) 50/50, and c) 30/70 blends as a function of temperature before and after UV irradiation

The crosslinked structure that occurs after UV radiation could have better ordered structures, but the crosslinking could be heterogeneous, and may result in agglomerations, which then present bad points in the structure, causing a breakage or cracking ${ }^{18,19}$. Accordingly, it is possible that after UV irradiation, the storage modulus decreased in all PU/ PC blends. 


\section{Thermogravimetric analysis}

The results of TGA measurement for the PU2 and PU4 elastomers before and after UV irradiation are presented in Table 4. It is clear that thermal degradation of PU elastomers occurs in two separate stages of degradation. The first stage of degradation represents the degradation of the hard segments, while the second stage represents the degradation of the soft segments ${ }^{20}$. The degradation temperature of the hard and soft segments of PU2 is at $236{ }^{\circ} \mathrm{C}\left(T_{\mathrm{i}}^{1}\right)$ and $370{ }^{\circ} \mathrm{C}\left(T_{i}^{2}\right)$, respectively. The increase in the hard segment content, PU4 elastomer, results in the shift of $\left(T_{i}^{1}\right)$ to higher temperature $\left(250{ }^{\circ} \mathrm{C}\right)$ and $\left(T_{\mathrm{i}}^{2}\right)$ to lower temperature $\left(361{ }^{\circ} \mathrm{C}\right)$. After UV irradiation of both elastomers, the third stage of degradation is evident due to the formation of crosslinked structures after photooxidative degradation. During thermal degradation of the elastomers in this temperature range, the urethane bond degraded upon UV irradiation and transferred into carbodiimide structures under heating ${ }^{21,22}$. For the irradiated PU2 and PU4 elastomers, the $\left(T_{\mathrm{i}}\right)$ and $\left(T_{\max }\right)$ shifted to higher temperatures in the first and second stages of degradation. In the third stage, both shifted to lower temperatures with the irradiation (smaller changes in the PU4 elastomer were observed) compared to unirradiated PU elastomers. After irradiation of PU2 elastomer, the second stage of degradation was not observed. The residue after $700{ }^{\circ} \mathrm{C}$ remained almost unchanged for both PU elastomers. These results suggest that the PU2 shows greater degradation with UV irradiation. The TGA results of the PC before and after UV irradiation are given in Table 4. The unirradiated PC shows no weight change up to $334{ }^{\circ} \mathrm{C}$, after which degradation occurs up to 521 ${ }^{\circ} \mathrm{C}$ in one step of degradation with $T_{\text {max }}$ at $500{ }^{\circ} \mathrm{C}$. The residue after $700{ }^{\circ} \mathrm{C}$ is $23.40 \%$, while the total weight loss for the PC is $75.93 \%$.

At higher temperatures, crosslinked polyaromatic carbonate residue is formed. The $\left(T_{\mathrm{i}}\right)$ of PC moves to higher temperature after UV irradiation. This suggests higher thermal stability probably due to the formation of crosslinking structure in the PC.

TG and DTG curves of the unirradiated and UV irradiated PU/PC blends are given in Figs. 7a-d, respectively, while the characteristic values for all blends are given in Table 4. All blends display three degradation steps, the first and second related to the degradation of the hard and soft segments in PU, while the third is related to the degradation of PC. The temperature of initial degradation in all blends shifted to lower temperatures compared to the PU

Table $4-T G A$ results before and after UV irradiation

\begin{tabular}{|c|c|c|c|c|c|c|c|}
\hline Sample & $\begin{array}{l}T_{\mathrm{i}}^{1} \\
{ }^{\circ} \mathrm{C}\end{array}$ & $\begin{array}{c}T_{\max }{ }^{1} \\
{ }^{\circ} \mathrm{C}\end{array}$ & $\begin{array}{l}T_{\mathrm{i}}^{2} \\
{ }^{\circ} \mathrm{C}\end{array}$ & $\begin{array}{l}T_{\max }^{2} \\
{ }^{\circ} \mathrm{C}\end{array}$ & $\begin{array}{l}T_{\mathrm{i}}^{3} \\
{ }^{\circ} \mathrm{C}\end{array}$ & $\begin{array}{c}T_{\max }^{3} \\
{ }^{\circ} \mathrm{C}\end{array}$ & $\begin{array}{l}\text { Residue at } \\
700{ }^{\circ} \mathrm{C}(\%)\end{array}$ \\
\hline PU2 & 236 & 325 & 370 & 380 & - & - & 3.46 \\
\hline PU2/PC 70/30 & 225 & 304 & 343 & 376 & 434 & 441 & 1.39 \\
\hline PU2/PC 50/50 & 235 & 29 & 322 & 371 & 397 & 401 & 2.39 \\
\hline PU2/PC 30/70 & 250 & 311 & 330 & 397 & - & - & 4.80 \\
\hline PU2 200 h UV & 241 & 330 & - & - & 421 & 442 & 4.29 \\
\hline PU2/PC 70/30 200 h UV & 238 & 335 & 348 & 367 & 434 & 446 & 3.86 \\
\hline PU2/PC 50/50 200 h UV & 248 & 344 & 360 & 382 & 433 & 440 & 3.87 \\
\hline PU2/PC 30/70 200 h UV & 272 & 320 & 325 & 396 & 434 & 438 & 4.07 \\
\hline PU4 & 250 & 318 & 361 & 374 & - & - & 7.82 \\
\hline PU4/PC 70/30 & 241 & 314 & 352 & 375 & 432 & 441 & 1.90 \\
\hline PU4/PC 50/50 & 240 & 303 & 336 & 365 & 387 & 391 & 2.12 \\
\hline PU4/PC 30/70 & 248 & 297 & 325 & 389 & - & - & 5.85 \\
\hline PU4 200 h UV & 268 & 329 & 380 & 392 & 433 & 446 & 3.47 \\
\hline PU4/PC 70/30 200 h UV & 248 & 328 & 355 & 365 & 423 & 447 & 3.58 \\
\hline PU4/PC 50/50 200 h UV & 261 & 313 & 342 & 362 & 419 & 446 & 2.38 \\
\hline PU4/PC 30/70 200 h UV & 271 & 314 & 337 & 397 & 420 & 440 & 4.28 \\
\hline PC & 334 & 500 & - & - & - & - & 23.40 \\
\hline PC 200 h UV & 391 & 503 & - & - & - & - & 24.46 \\
\hline
\end{tabular}

$T_{\mathrm{i}}^{1,2,3}$ - initial temperature of the first, second, and third degradation steps; $T_{\max }^{1,2,3}$ - maximum degradation temperature 
a)

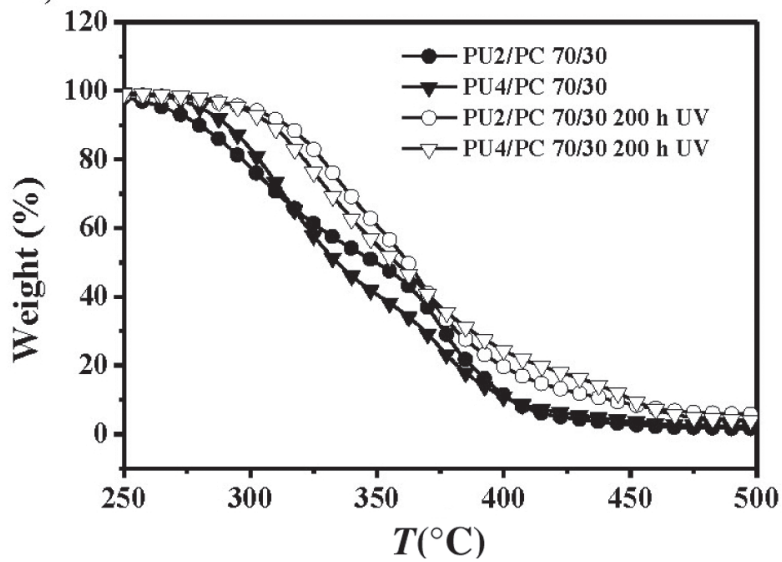

c)

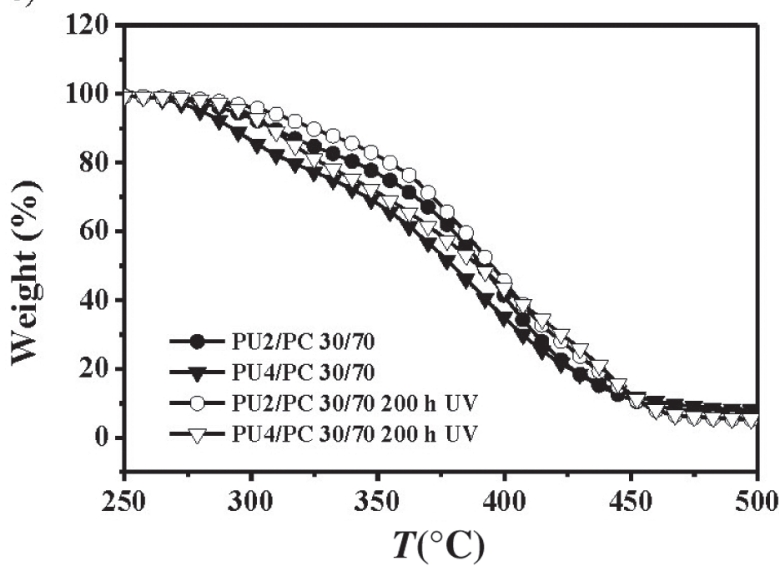

b)

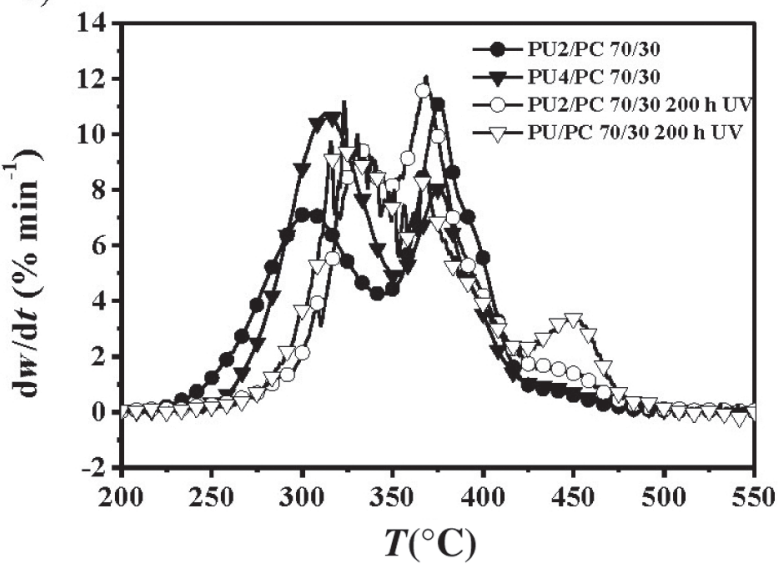

d)



Fig. 7 - TG and DTG curves of: a) and b) PU/PC 70/30 blends, and c) and d) 30/70 blends before and after UV irradiation

elastomers, but the temperatures increased with the increase in the hard segment and PC content. The changes are greater in the PU2/PC blends with the smaller content of the hard segment, which means that the hard segment had no interaction with the PC. The residue after $700{ }^{\circ} \mathrm{C}$ increases with the increase in the PC content in all PU/PC blends.

After UV irradiation, the initial degradation temperatures $T_{i}^{1}$ and $T_{i}^{2}$ increase in all blends compared to the unirradiated PU/PC blends, suggesting that the thermal stability is increased, which is connected to the formation of the crosslinked structures. The residue at $700{ }^{\circ} \mathrm{C}$ is greater after UV irradiation, which is also a result of the crosslinking structure formed by the influence of the UV light. The described changes are greater for the PU4/PC blends (Table 4).

\section{Tensile properties}

The effect of the hard segment content and UV irradiation on the mechanical properties of PU/PC blends is shown in Fig. 8. The values of tensile strength $(\sigma)$, elongation at break $(\varepsilon)$ and modulus $(E)$, obtained from the stress-strain curves are presented in Table 5. With increasing of the hard seg- ment and PC content in the PU4/PC blends, the mechanical properties increased significantly before UV irradiation, thus materials stiffness increased. These results are in good agreement with the results of thermal analysis. With increasing hard segment content in the PU4/PC blends, $\sigma$ did not change after UV irradiation. The UV irradiation results in the reduction of the tensile strength of the PU2/PC blends. According to the results of elongation at break in Table 5, $\varepsilon$ increases in all PU/PC blends, which could be due to less photodegraded soft segment after UV irradiation.

The stress-strain dependence remained the same after UV irradiation for the PC, which indicated that the mechanical properties of the PC had not changed significantly under the conditions of the experiment.

\section{Conclusion}

In this study, the effect of the hard segment content on the thermal and mechanical properties of $\mathrm{PU} / \mathrm{PC}$ blends before and after UV irradiation has been investigated. According to the DSC results, with the increase in hard segment content in PU/PC 

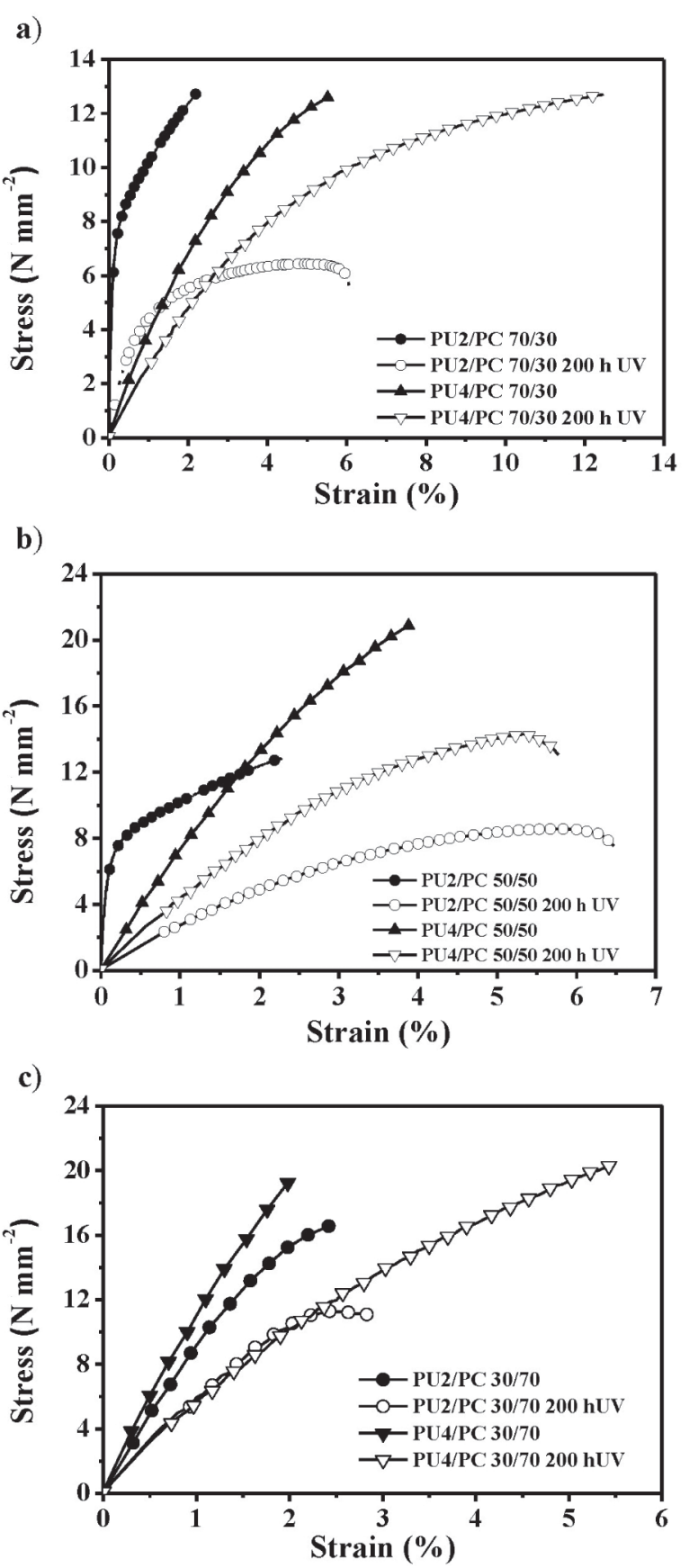

Fig. 8 - Stress-strain curves of the PU/PC blends a) 70/30, b) 50/50, and c) 30/70 before and after UV irradiation

blends, the melting temperatures increased before and after UV irradiation. The observed results indicated the formation of crosslinked structures with higher ordering. DMA study revealed that the PU/ PC blends exhibited two distinct $T$, representing one of the PU at lower temperature and one of PC at higher temperature, respectively. The $T_{\mathrm{g}}$ 's of the PU and PC phases shifted towards each other, demonstrating that PU and PC had formed partial miscible blends. These results may be explained by PU urethane groups' possible interaction with the carbonyl groups from the PC. The higher hard seg-
Table 5 -Mechanical properties before and after UV irradiation

\begin{tabular}{lcccc}
\hline \multicolumn{1}{c|}{ Samples } & $\sigma(\mathrm{MPa})$ & $\varepsilon(\%)$ & $E(\mathrm{MPa})$ \\
\hline PU2 & 2.3 & 38.0 & 18.10 \\
PU2/PC 70/30 & 6.3 & 3.0 & 136.08 \\
PU2/PC 50/50 & 12.8 & 2.3 & 457.85 \\
PU2/PC 30/70 & 16.6 & 2.0 & 950.23 \\
\hline PU2/PC 70/30 200 h UV & 5.7 & 6.1 & 87.06 \\
PU2/PC 50/50 200 h UV & 7.5 & 5.7 & 285.07 \\
PU2/PC 30/70 200 h UV & 11.1 & 2.5 & 650.92 \\
\hline PU4 & 13.6 & 36.0 & 181.11 \\
PU4/PC 70/30 & 12.6 & 6.0 & 424.46 \\
PU4/PC 50/50 & 13.3 & 5.0 & 750.33 \\
PU4/PC 30/70 & 20.9 & 2.0 & 1239.11 \\
\hline PU4/PC 70/30 200 h UV & 12.7 & 12.5 & 269.62 \\
PU4/PC 50/50 200 h UV & 13.1 & 5.8 & 460.65 \\
PU4/PC 30/70 200 h UV & 20.4 & 5.5 & 629.36 \\
\hline PC before irradiation & 59.2 & 14.2 & 859.59 \\
PC (200 h UV) & 59.2 & 14.2 & 859.59 \\
\hline$\sigma-$ tensile strength, $\varepsilon-$ elongation at break, & $E-$ Young modulus
\end{tabular}

ment content increased $T_{\mathrm{g}}$ and decreased mobility of the soft segment before and after UV irradiation. The storage modulus of the PU/PC blends, which is proportional to the rigidity of a polymer, increased with an increase in the hard segment and PC content before UV irradiation. All irradiated PU/PC blends showed a decrease in the storage modulus. The thermal degradation of all PU/PC blends in nitrogen consists of three degradation stages; the first stage is related to the decomposition of the hard segment, in the second stage the soft segment degrades, while the third step is related to the degradation of the PC. The temperature of the initial degradation in all blends shifted to higher temperatures with the increase in the hard segment content. After UV irradiation, the higher values of $T$ indicate higher thermal stability of UV-exposed PU/PC blends at the beginning of degradation. The increase in the degradation temperature is probably due to formation of the crosslinking structure after photooxidative degradation. However, UV exposed PU/PC blends degraded more easily than unexposed blends. The results of the stress-strain measurements showed that the higher hard segment content improved the mechanical properties in all investigated PU/PC blends before and after UV irradiation. Photooxidation is believed to take place in aromatic urethanes, where the urethane bridge oxidizes to a 
quinone-imide structure. This structure is a strong chromophore, resulting in the yellowing of urethanes. All observed results showed that PU4/PC blends had a higher resistance to thermal and UV degradation compared to PU2/PC blends, which is the most important contribution of this work.

\section{ACKNOWLEDGMENT}

This work has been fully supported by the short-term financial support for the research of the University of Zagreb.

\section{CONFLICT OF INTERESTS} interest.

The authors declare that there is no conflict of

\section{References}

1. Zhao, Q., Li, X., Gao, J., Agingofethylene-propylene-dienemonomer (EPDM) in artificial weather in environment, Polym. Degrad. Stab. 92 (2007) 1841.

2. Oprea, S., Oprea, V., Mechanical behavior during different weathering tests of the polyurethane elastomers films, Eur. Polym. J. 38 (2002) 1205. doi: https://doi.org/10.1016/S0014-3057(01)00280-4

3. Torikai, A., Murata, T., Fueki, K., Photo-induced reactions of polycarbonate studied by ESR, viscosity and optical absorption measurements, Polym. Photochem. 4 (1984) 255. doi: https://doi.org/10.1016/0144-2880(84)90047-2

4. Schultze, $H$., Über den photochemischenabbau von polyurethanen, Makromol. Chem. 172 (1973) 57. doi: https://doi.org/10.1002/macp.1973.021720105

5. Beachell, H. C., Chang, I. L., Photodegradation of urethane model systems, J. Polym. Sci. Part A-1 10 (1972) 503. doi: https://doi.org/10.1002/pol.1972.150100216

6. Rivaton, A., Recent advances in bisphenol A polycarbonate photodegradation, Polym. Degrad. Stab. 49 (1995) 163 doi: https://doi.org/10.1016/0141-3910(95)00069-X

7. Migahed, M. D., Zidan, H. M., Influence of UV-irradiation on the structure and optical properties of polycarbonate films, Curr. Appl. Phys. 6 (2006) 91. doi: https://doi.org/10.1016/j.cap.2004.12.009

8. Wilhelm, C., Gardette, J. L., Infrared analysis of the photochemical behaviour of segmented polyurethanes: Aliphatic poly(ether-urethane)s, Polymer 39 (1998) 5973.

9. Briber, R. M., Thomas, E. L., The structure of MDI/BDObased polyurethanes: Diffraction studies on model compounds and oriented thin films, J. Polym. Sci. Part B Polym. Phys. 23 (1985) 1915.

10. Sohn, S., Alizadeh, A., Marand, H., On the multiple melting behavior of bisphenol-A polycarbonate, Polymer 41 (2000) 8879 .

doi: https://doi.org/10.1016/S0032-3861(00)00110-5
11. Boubakri, A., Guermazi, N., Elleuch, K., Ayedi, H. F., Study of UV-aging of thermoplastic polyurethane material, Mater. Sci. Eng. 527 (2010) 1649. doi: https://doi.org/10.1016/j.msea.2010.01.014

12. Kim, Y., Cho, W. J., Ha, C. S., Dynamic mechanical and morphological studies on the compatibility of plasticized PVC/thermoplastic polyurethane blends, J. Appl. Polym. Sci.71 (1999) 415. doi: https://doi.org/10.1002/(SICI)1097-4628(19990118)71 :3<415::AID-APP7>3.0.CO; 2-Z

13. Potschke, P., Wallheinke, K., Fritsche, H., Stutz, H., Morphology and properties of blends with different thermoplastic polyurethanes and polyolefines, J. Appl. Polym. Sci. 64 (1997) 749.

doi: https://doi.org/10.1002/(SICI)1097-4628(19970425)64 :4<749::AID-APP14>3.0.CO; 2-P

14. Fambri, L., Penati, A., Kolarik, J., Modification of polycarbonate with miscible polyurethane elastomers, Polymer $\mathbf{3 8}$ (1997) 835. doi: https://doi.org/10.1016/S0032-3861(96)00562-9

15. Samions, C. K., Kalfoglou, N. K., Compatibility characterization of polycarbonate/copolyester blends, Polymer 41 (2000) 5759. doi: https://doi.org/10.1016/S0032-3861(99)00803-4

16. Ahn, T. O., Jung, S., Lee, J., Jeong, H. M., Influence of interchange reactions on the miscibility of polyesterurethanes/polycarbonate binary blends, J. Appl. Polym. Sci. 64 (1997) 2363 doi: https://doi.org/10.1002/(SICI)1097-4628(19970620)64 $: 12<2363:: A I D-A P P 11>3.0 . C O ; 2-2$

17. Claude, B., Gonon, L., Duchet, J., Verney, V., Gardette, $J$. L., Surface cross-linking of polycarbonate under irradiation at long wavelengths, Polym. Degrad. Stab. 83 (2004) 237. doi: https://doi.org/10.1016/S0141-3910(03)00267-2

18. Neilsen, L. E., Mechanical properties of polymers and composites. Marcel Dekker, New York,1974, p. 556

19. Lee, H. K., Ko, S. W., Structure and thermal properties of polyether polyurethane urea elastomers, J. Appl. Polym. Sci. 50 (1993) 1269. doi: https://doi.org/10.1002/app.1993.070500718

20. Grassie, N., Macherron, D. H., Synthesis and degradation of polyurethanes containing phosphorus-Part III: Thermal degradation of a series of polyurethanes incorporating butylene phenyl phosphonate structures, Polym. Deg. Stab. 5 (1983) 89. doi: https://doi.org/10.1016/0141-3910(83)90002-2

21. Grassie, N., Mendoza, G. A. P., Thermal degradation of polyether-urethanes: Part 2-Influence of the fire retardant, ammonium polyphosphate, on the thermal degradation of poly (ethylene glycol), Polym. Deg. Stab. 10 (1985) 43 doi: https://doi.org/10.1016/0141-3910(85)90019-9

22. Grassie, N., Mendoza, G. A. P., Thermal degradation of polyether-urethanes: Part 4-Effect of ammonium polyphosphate on the thermal degradation of polyether-urethanes prepared from methylene bis(4-phenylisocyanate) and low molecular weight poly(ethylene glycols), Polym. Deg. Stab. 11 (1985) 145 doi: https://doi.org/10.1016/0141-3910(85)90107-7 